\title{
B.B. ШחAK,
}

Институт микроприборов и систем управления им. Л.Н. Преснухина НИУ «МИЭТ»

(Москва, Российская Федерация; e-mail: mishinevaiv@minprom.gov.ru)

\section{СТРАТЕГИЯ РАЗВИТИЯ ЭЛЕКТРОННОЙ ПРОМЫШЛЕННОСТИ РОССИЙСКОЙ ФЕДЕРАЦИИ И ЕЁ ФИНАНСОВОЕ ОБЕСПЕЧЕНИЕ}

I УДК: $336.1,336.13,351.72$

1 https://doi.org/10.22394/2410-132X-2021-7-3-195-204

Аннотация: Целью статьи является обоснование пути решения задачи, поставленной Президентом России, I по достижению суверенитета в сфере разработки и производства электроники и электронной компонентной 1 базы. Методы достижения этой цели разработало Правительство и утвердило Стратегию развития электронной промышленности до 2030 года. Наиболее мощным и динамично развивающимся конкурентом отечественной электроники является Китай, поэтому рассмотрение вопросов развития отечественной электроники

I целесообразно осуществлять, имея в качестве масштабной линейки изоморфные процессы на отдельных 1 предприятиях и в электронике Китая. Сейчас выявилось узкое место в развитии отечественной электроники I это отсутствие упреждающего и дублирующего финансирования прорывных технологий. В статье представлен 1. ассиметричный вариант ответа на тотальные и усиливающиеся западные санкции, главным элементом которого должны будут стать неденежные инвестиционные сертификаты.

Ключевые слова: электронная промышленность, стратегия, неденежные инвестиционные сертификаты, I электронная компонентная база, демередж

I Для цитирования: Шпак В.В. Стратегия развития электронной промышленности Российской Федерации I. и её финансовое обеспечение. Экономика науки. 2021; 7(3):195-204. https://doi.org/10.22394/2410-

I 132X-2021-7-3-195-204

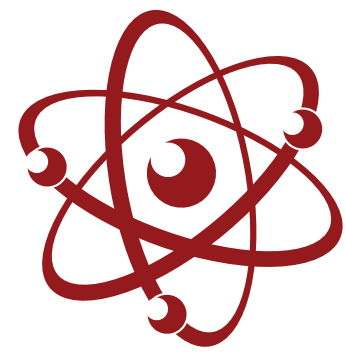

\section{ВВЕДЕНИЕ}

l елью настоящей работы является поиск источников полного и своевременного финансирования стратегии развития электроники в нашей стране. Сравнение объёмов средств, вкладываемых нашими конкурентами в развитие электроники, с объективными возможностями нашего бюджета и всеми коммерческими инвестициями, которые осуществляются в российских рублях или в иностранных резервных валютах, однозначно свидетельствуют о том, что для осуществления промышленного прорыва необходимо найти качественно новое средство обращения. Оно по своей внутренней структуре должно быть инвестиционным, не подверженным инфляции, «намертво привязано» к электронике и отраслям, обеспечивающим её ускоренное развитие, а также исключающим любые корыстные, коррупционные и прочие схемы. Такое средство удалось представить общественности группой учёный, работающих в Российском экономическом университете им. Г.В. Плеханова. Автор статьи именует их «неденежными инвестиционными сертификатами».

Россия в целом и электронная промышленность в частности развиваются в окружении активных, а иногда и весьма агрессивных конкурентов, которые ради продвижения своих коммерческих интересов в мире готовы не только на меры здоровой конкуренции, но и на безосновательные санкции, политическое давление с позиции силы и даже прямые нескрываемые угрозы. В научной статье мы оставим за рамками её предмета 
нашей экономики через призму действий восточного конкурента России в сфере высоких технологий. Китайская сопоставительная шкала, особенно в вопросах финансирования прорывных технологий в электронике, позволяет наглядно оценивать уровень и динамику развития отечественной отрасли.

\section{СТРАТЕГИИ РАЗВИТИЯ ЭЛЕКТРОНИКИ В РОССИИ И В КИТАЕ}

Главным действующим лицом в высоких технологиях является высокообразованный и хорошо мотивированный специалист. Коммунистическая партия Китая к столетнему юбилею в нынешнем году выделила победу над бедностью в качестве своего важнейшего достижения, которое является фундаментом научно-технологического развития страны. Если подводить предельно краткий итог достижений Китая в сфере благосостояния граждан, то можно опереться на широко известный факт: из полутора миллиардов жителей этой страны три четверти, как минимум, активно пользуются интернетом, что демонстрирует рост благосостояния населения.

Аналогичную задачу обеспечения достатка гражданам нашей страны неоднократно озвучивал и Президент России. Особенно это касается специфической российской категории «работающих бедных». Если взять докризисные и допандемийные данные [1], то почасовая оплата работающих на производстве специалистов в Европе составляла от 34,53 евро в Швеции до 24,25 евро в Италии. В то же время в США специалисты получали в среднем 22,57 евро в час, а в Японии - 18,39 евро в час [2]. Данные в условиях турбулентности трудно сопоставить с показателями начала XXI века, но даже взятая 12 лет назад планка оплаты в странах-конкурентах России для нашей экономики пока представляется недостижимой. Так в 2021 г. минимальный размер оплаты труда (МРОТ) составляет 12792 руб. (в 2020 г. он составлял 12130 руб.), а средняя заработная плата по стране в 2020 г. была 33000 руб. в месяц. МРОТ 2021 г. определён для 40-часовой рабочей недели. Если взять за максимум в рабочем месяце 184 часа, то часовой МРОТ в 2021 г. составит 12792/184= 69,52 руб. Для примера в США установлен федеральный минимальный уровень оплаты в 7,25 долл. При условном курсе 77 руб. за доллар это более 558 руб. в час, а минимальная месячная зарплата в США должна быть эквивалентной почти 97 тысячам руб. При этом выйти на паритетные уровни оплаты С конкурентами традиционными методами в текущих условиях не представляется возможным. Поэтому вопрос о повышении оплаты труда, в первую очередь в прорывных технологиях электроники, без введения дополнительного второго контура невозможен.

По расчётам специалистов, с 1984 г. реальные доходы населения России возросли на 34\%, тогда как китайская экономика обеспечила рост на $831 \%$. Рост реальных доходов населения в Индии оценивается в $221 \%$. В мире в целом этот показатель вырос на 60\%, то есть он рос в два раза быстрее, чем в нашей экономике [3]. При таком кратном отставании, с одной стороны, трудно развивать высокотехнологические производства мирового уровня, a, с другой стороны, практически невозможно сдержать переезд наиболее квалифицированных специалистов в страны-конкуренты.

Руководителей российской экономики, работающих с полной самоотдачей, в сложившейся ситуации обвинить было бы несправедливо. Невозможно возложить вину в этом провале на самих работников и специалистов, так как вопреки поручению Президента России [4] владельцы предприятий неоправданно медленно создают 25 миллионов высокопроизводительных и высокооплачиваемых рабочих мест. Корень проблемы в том, что действующая в стране валютно-финансовая система, захватив абсолютную монополию в экономике, диктует производителям свою кредитную политику, которая смотрится как субъективная аномалия на фоне практически бесплатной раздачи инвестиционных средств в странах-конкурентах. Это структурообразующий фактор, с которым надо считаться при выполнении задач Стратегии развития электроники в России.

Второй элемент стратегии Китая - главного конкурента России в области электроники это запланированное на 2049 г. «возрождение 
великой китайской нации». При этом руководство Китая не призывает обратиться к традициям и старине, а направляет свои усилия на осуществление очередного «большого» скачка в будущее, который предусмотрен в XIV пятилетнем плане развития страны. Краеугольным камнем стратегии экономики Китая являются наука и технологии, включая «искусственный интеллект», полупроводники, квантовые компьютеры и т.п. Только в 2020 г. в «research and development» (R\&D), то есть исследования и разработки, китайское правительство инвестировало сумму, эквивалентную 378 млрд. долл. или более 26 трлн. руб. за один год [5], что соответствует четверти всего бюджета Российской Федерации в 2020 году. В планах на ближайшую пятилетку - увеличить эти расходы на 10 процентов. Причём эти суммы расходуются не только на выполнение госконтрактов, но и на создание благоприятной научно-коммерческой среды. В Китае учёные, создающие прорывные технологии, с 2019 г. получили право брать оплачиваемый отпуск продолжительностью до шести лет для коммерциализации собственных разработок. При этом им не только предоставляется инфраструктура и инвестиции, но и в полном объёме выплачивается зарплата на достигнутом уровне, а также сохраняются все заслуженные ранее льготы и привилегии. Эти годы засчитываются учёным в научный стаж и высоко ценятся в китайской академической системе научного роста.

В настоящее время в рейтинге учёных, занятых в создании и развитии сферы, именуемой «искусственный интеллект», подавляющее большинство мест в первой сотне занимают специалисты, проживающие в США. При этом большая часть этих «интеллектуальных локомотивов» приехали в США уже как подготовленные в других странах специалисты, в том числе и из России. По данным переписи населения в США проживает около 3 миллионов русских. Реально русскоговорящих от 4 до 5,5 миллионов человек. Средний доход русских эмигрировавших специалистов составляет 47 тысяч долл. в год, причём четверть из них имеют доход выше 50 тысяч долл., что выше доходов самих американцев - 38866 долл. в год и китайцев 42199 долл. в год [6]. Китай вынужденно или сознательно делает ставку на воспитание своих собственных специалистов, в том числе, направляя их на некоторое время для стажировки, а точнее для «впитывания» новых знаний в ведущие исследовательские центры мира. Им удалось создать такой социально-экономический климат в научной и образовательной среде, при котором новые специалисты осваивают высокотехнологичные специальности, а уехав на несколько лет, они активно возвращаются в Китай для служения своей родине. В китайских университетах экспоненциально растёт количество новых мест для профессоров в электронике и высоких технологиях. Тысячи заведений для подготовки специалистов в области искусственного интеллекта создаются по всей стране как единая и хорошо финансируемая национальная сеть. Поэтому ещё в 2005 г. китайские учёные опередили весь мир по количеству научных статей об искусственном интеллекте, а в прошлом году китайские публикации уже обошли США по цитируемости научных работ, посвящённых этой теме. И опять же финансирование этого и аналогичных китайских прорывов не в разы, а на порядки больше того, что предусматривается в России [7].

Президент России также призывает к прорыву, но, как показывает сегодняшний опыт Китая, без аналогичных финансовых условий для отечественных учёных и разработчиков трудно реализовать эти планы на практике. Существующая валютно-финансовая система за время её существования не только не обеспечила аналогичные условия для развития электроники и других сфер экономики шестого технологического уклада, но даже не имеет аналогичных с Китаем планов реализации президентского прорыва в мир будущих цифровых технологий.

\section{ПРОБЛЕМА БЮДЖЕТНОГО ФИНАНСИРОВАНИЯ И ОБОРОТНЫХ СРЕДСТВ ЭЛЕКТРОНИКИ}

В «Стратегии развития электронной промышленности Российской Федерации на период до 2030 года» (далее - Стратегия), которая разработана в целях обеспечения максимально возможного технологического развития, установлено, что источниками ресурсного обеспечения её реализации должны стать: 
- средства федерального бюджета, предусмотренные на реализацию государственных программ Российской Федерации;

- средства Фонда перспективных исследований, Фонда развития промышленности и других институтов развития;

- средства бюджетов субъектов Российской Федерации;

- ресурсы организаций электронной промышленности;

- средства частных инвесторов, в том числе в рамках реализации инвестиционных проектов с государственным участием;

- средства иных участников хозяйственной деятельности [8].

Исполнители мероприятий Стратегии активно приступили к выполнению её технических и технологических задач. Однако темпы финансирования этих работ отстают от реальных сроков расчётов за выполненные работы, предоставленные услуги и поставленные по кооперации материальные объекты. Систематическое отставание процедур финансирования мероприятий Стратегии от сроков наступления финансовых обязательств хозяйствующих субъектов объективно приводит к необходимости получения ими кредитов. Это финансово обескровливает предприятия отрасли и существенно увеличивает себестоимость выпускаемой продукции, снижая её ценовую конкуренцию даже на отечественном рынке.

В декабре 2018 г. вице-премьер Ю. Борисов отметил, что «российская оборонка оказалась в долговом болоте». Только проценты предприятий по кредитам составляют около 135 млрд. руб. в год [9]. И эти миллиарды не предусмотрены в гособоронзаказе, а до предела снижают рентабельность предприятий, уровень оплаты труда работников и, в конечном счете, приводят к удорожанию продукции для покупателей электроники, в цену которой включаются банковские проценты по вынужденным кредитам.

Цифровые технологии опираются на компьютеры, которые, в свою очередь, собираются из частей, которые в обобщённом виде можно назвать электронной компонентной базой (далее - ЭКБ). До 34\% от всей ЭКБ используется в различных устройствах, обобщённо именуемых «компьютеры», в смартфонах - 14\%, в автомобилях - 8\%, в экономическом воспроизводственном цикле - 36\% и в других сферах ещё 8\% [10]. Концепции интернета вещей, умного дома, умного города и т.п. вынуждают оснащать ЭКБ сантехнику, светофоры, холодильники, утюги и даже «умную одежду». Для полной реализации цифровых технологий требуется количество ЭКБ в разы, если не на порядки, больше, чем сейчас производится в мире. Сейчас большая часть номенклатуры ЭКБ разрабатывается в США, а производится в Азии. Ресурсы для их производства добывают по всему миру, и Россия является одной из ведущих стран-поставщиков исходного сырья. В нашей стране производство ЭКБ находится в зачаточном состоянии и способно обеспечить только базовые потребности в специальных сегментах с низкой серийностью. При этом, приобретать ЭКБ на внешних рынках становится всё труднее. Так, за время пандемии Китай, не взирая на наличие собственного производства ЭКБ, активно скупал их по всему миру. Американцы требовали, чтобы Китай в разы увеличил импорт американских товаров для балансировки торгового и платёжного балансов между странами. Китай внял требованиям и направил каждый пятый доллар на импорт ЭКБ. Общая сумма расходов по этой статье превысила 380 млрд. долл. Теперь многие страны столкнулись с дефицитом ЭКБ, особенно самых ходовых типономиналов, а на складах китайских корпораций, например, Huawei, созданы запасы, которые позволяют полностью игнорировать угрозы санкций и ограничений, заявленных Дональдом Трампом ещё в 2018 г. До 60\% всей ЭКБ в мире используется китайскими производителями. Сейчас они способны производить лишь треть необходимой им номенклатуры ЭКБ, но объёмы финансирования этой сферы и темпы наращивания собственного производства просто не с чем сравнивать в мировой экономике.

В 2020 г. инвестиции в китайские фирмы, выпускающие ЭКБ по полному циклу от создания материалов и Систем автоматизированного проектирования (САПР) до конечного производства выросли в четыре раза всего за год. Такой темп роста планируется выдерживать в будущем. Кроме агрессивных малых 
и средних компаний в области производства ЭКБ к этому процессу всё активнее подключаются Xiaomi, Huawei, Oppo и другие гиганты. Например, флагманский китайский поисковик Baidu специализируется на производстве ЭКБ для автомобилей будущего. Владелец корпорации Alibaba Джек Ма в качестве своей специализации выбрал ЭКБ для облачных платформ и так называемого искусственного интеллекта. Корпорация ByteDance, развивающая торговую марку социальной сети TikTok, поставила задачу достижения максимального самообеспечения ЭКБ для своих серверных центров. И эти примеры можно продолжать. При таких темпах инвестиций в материальные факторы производства и в массовое обучение персонала для будущих производств ЭКБ в самые ближайшие году Китай обойдёт США по производству ЭКБ и, по всей вероятности, сможет освободиться от пока ещё высокой технологической зависимости.

В России идёт поиск новых идей, особенно, в области исследования и формирования принципиально новых подходов к обеспечению финансирования высокотехнологичных отраслей. В частности, по заказу Минобрнауки РФ научный коллектив ФГБОУ ВО «РЭУ им. Г.В. Плеханова» совместно с учёными Финуниверситета, выполнил научно-исследовательскую работу на тему «Обоснование параметров модели двухконтурной национальной валютно-финансовой системы и её практического применения в Российской Федерации» [11]. Полученные предварительные результаты российские учёные опубликовали в виде научной монографии [12].

Предложенная в монографии «Модель двухконтурной системы в сфере обращения экономики России» представляется важным шагом в разрешении противоречия, описанного в начале настоящей статьи. Безусловно, новая разрабатываемая система не сможет полностью заменить рублёвое и валютное финансирование мероприятий Стратегии. Её инструменты следует использовать не вместо бюджетного финансирования проектов и программ, а в дополнение и в периоды, когда предприятия вынуждены согласно действующим процедурам брать коммерческие кредиты и попадать в долговую зависимость от коммерческих банков.

Авторы монографии утверждают, что инструментами второго контура сферы обращения экономики России должны стать небанковские и неденежные сертификаты.

В основу этой своевременной разработки легли известные фундаментальные тезисы

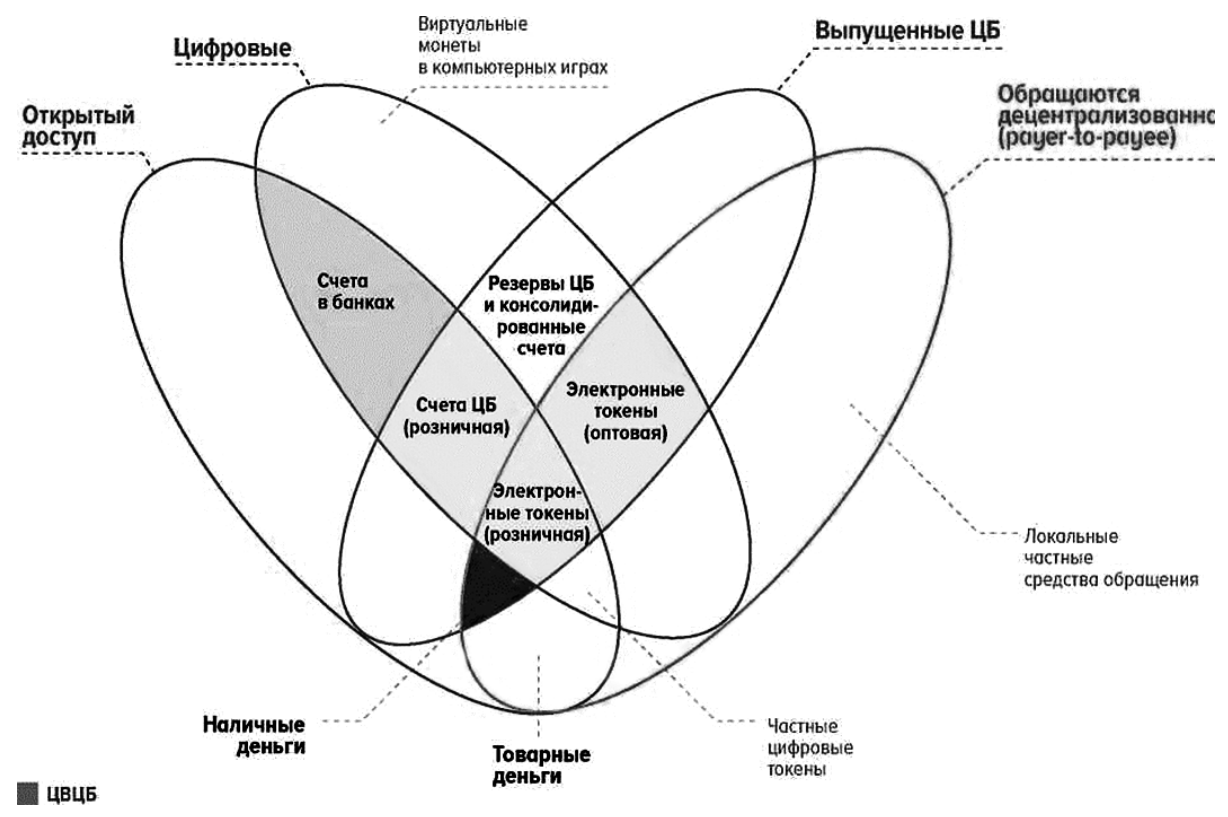

Рисунок 1. Типология финансовых активов по эмитентам, формам, доступности и технологиям

Источник: Цифровой рубль. Доклад для общественных консультаций. М.: Банк России, октябрь, 2020 
аргентино-немецкого учёного Сильвио Гезеля [13]. Его «деньги с демереджем» или «свободные (от ссудного процента) деньги» не только известны, но и многократно успешно апробировались в мире, особенно в кризисных ситуациях. В условиях нарастающих санкций со стороны западных конкурентов и применения нерыночных методов конкуренции, включая демпинг на российском рынке, запуск этого или аналогичного средства обращения позволит эффективно и ассиметрично ответить на вызовы, искусственно формируемые перед российской эКОНОМикой.

Не вдаваясь в тонкости теории и сущности «денег с демереджем», в практическом плане можно приветствовать введение такого качественно нового средства обращения по многим параметрам, тем более что нечто аналогичное проанонсировано в известном Докладе Банка России о цифровом рубле [14], на рисунке 1 представлена типология финансовых активов по эмитентам, формам, доступности и технологиям.

Наиболее значимым преимуществом новых средств обращения в частности, и второго контура в целом, является то, что им будут распоряжаться специализированные органы исполнительной власти, а не коммерческие банковские структуры, интересы которых состоят в максимизации собственной прибыли, а не создание комфортных макроэкономических условий для производителей и потребителей электроники. Предлагаемый учёными РЭУ им. Г.В. Плеханова «Совет по пропорциям и динамике» при Президенте РФ будет выпускать новые средства обращения, контролировать баланс между ценностной массой товаров, работ, услуг на рынке электроники и стоимостным эквивалентом выпущенных неденежных инвестиционных сертификатов с учётом реальной скорости их обращения. Эта схема может стать намного более естественной и эффективной нежели сегодняшняя неравноправная конкуренция между коммерческими банками и производителями за долю добавленной стоимости, создаваемой в секторах реальной экономики. Данное антагонистическое противоречие воспроизводственного цикла с помощью неденежных инвестиционных средств обращения предлагаемого второго контура будет снято, потому что
«Совет по пропорциям и динамике» не будет претендовать на долю добавленной стоимости, которую производители смогут дополнительно направить на развитие новых производств и повышение оплаты труда работников.

Наиболее эффективным элементом новых неденежных инвестиционных средств обращения представляется завершающий этап выполнения заданий государственных органов, в результате которого у исполнителей формируется доход в этих новых небанковских и неденежных средств обращения, который они, по предложению авторов разработки, могут израсходовать на приобретение самых передовых технологий и оборудования по льготному обменному курсу, котируемому Банком России [15].

Если данную норму ввести в практику выполнения Стратегии и других государственных программ и Национальных проектов, включая гособоронзаказ, то она позволит кардинально переломить негативную тенденцию физического и морального износа основных производственных фондов в экономике страны. Наиболее эффективной данная мера может стать в электронной промышленности, так как скорость устаревания материально-технического и технологического обеспечения производства здесь одна из самых высоких. Очень часто замены требует ещё вполне работоспособное, но морально устаревшее оборудование в силу динамичного развития научной мысли и технологических достижений учёных и специалистов.

Электроника как структурообразующая отрасль современной экономики от внедрения в практику второго небанковского, неденежного средства обращения, основанного на современных цифровых технологиях, выиграет, по крайней мере, дважды. Во-первых, достаточное количество средств обращения, выделенных предприятиям отрасли своевременно, обеспечит выполнение и перевыполнение мероприятий Стратегии, по насыщению отечественного рынка более дешёвой электроникой собственного производства по полному воспроизводственному циклу. Во-вторых, широкое применение цифровых технологий в сфере обращения существенно увеличит платёжеспособный спрос на продукцию отрасли. Это станет мощным локомотивом, который позволит реализовать 
задачу президентского прорыва в следующий технологический уклад. Предприятия отрасли с научной и технологической сторон готовы к этому прорыву. Сдерживающим фактором остаётся недостаточное и запаздывающее финансирование проектов и программ, особенно фундаментального характера, который может быть целенаправленно устранён благодаря введению неденежных инвестиционных сертификатов - второго небанковского, неденежного контура обращения.

\section{ОБСУЖДЕНИЕ}

На сегодняшний день общая потребность в финансировании электронной промышленности в перспективе до 2030 г. по минимальным оценкам составляет 1 трлн. руб. Если же ставить цель по достижению темпов роста китайской электроники, то эта цифра должна будет вырасти, как минимум, на порядок, что физически невозможно при нынешнем размере бюджета и при экстраполяции достигнутого уровня внебюджетного финансирования проектов электронной промышленности, особенно фундаментальных исследовательских работ.

Наиболее перспективными на текущий день сферами развития в электронике можно назвать радиофотонику, квантовые вычисления и коммуникации, технологии связи 6G, нейроморфные технологии. Важно отметить, что при наличии необходимых ресурсов, Россия вполне может стать одним из мировых лидеров в развитии этих технологий, т.к. все они находятся ещё в достаточно раннем состоянии, и у нас есть научные группы и коллективы, имеющие существенные наработки по этим тематикам. Сейчас перспективные работы государство вынуждено финансировать по остаточному принципу, фокусируясь на тех задачах, которые смогут обеспечить краткосрочный результат.

Дополнение рублёвого финансирования новыми средствами обращения - неденежными инвестиционными сертификатами позволило бы электронной промышленности обеспечить нужный технологический рывок «в обгон» современных лидеров, занять достойное место на международном уровне и обеспечить высокие темпы развития всей экономики страны.

Особо остро в отрасли чувствуется дефицит оборотных средств, которые необходимы, например, для формирования массового заказа на производство современных отечественных микропроцессоров, таких как Эльбрус и Байкал, которые, к сожалению, производятся на фабриках Китая и Тайваня. Восполнение оборотных средств за счёт неденежных инвестиционных сертификатов позволило бы опережающими темпами обеспечить выполнение планов по импортозамещению и переходу на использование отечественной электронной компонентой базы.

Официальная статистика обеспеченности отраслей реальной экономики оборотными средствами на уровне поддержания эффективного производства представляется не вполне адекватной задачам, поставленным Президентом России (таблица 1).

\section{Коэффициент обеспеченности предприятий России собственными оборотными средствами на 1 января по годам, в \%}

\begin{tabular}{|c|c|c|c|c|c|c|c|}
\hline \multirow{2}{*}{ Название отрасли } & \multicolumn{7}{|c|}{ Год } \\
\hline & 2005 & 2008 & 2010 & 2012 & 2014 & 2016 & 2017 \\
\hline Всего & $-5,8$ & $-13,7$ & $-20,3$ & $-16,5$ & $-26,4$ & $-21,5$ & $-21,0$ \\
\hline $\begin{array}{l}\text { Обрабатывающая } \\
\text { промышленность }\end{array}$ & $-7,6$ & $-4,4$ & $-15,8$ & $-13,9$ & $-34,8$ & $-31,3$ & $-39,3$ \\
\hline Сельское хозяйство & $-11,9$ & $-26,6$ & $-37,2$ & $-43,1$ & $-43,8$ & $-18,7$ & $-16,2$ \\
\hline Добыча полезных ископаемых & 7,9 & 0,67 & $-17,7$ & $-17,9$ & $-35,7$ & $-21,5$ & $-13,4$ \\
\hline Металлургическое производство & 21,5 & 23,3 & $-18,9$ & $-20,4$ & $-42,7$ & $-41,5$ & $-44,9$ \\
\hline $\begin{array}{l}\text { Добыча природного газа } \\
\text { и газового конденсата }\end{array}$ & $-65,2$ & $-79,4$ & -113 & -134 & -138 & $-101,5$ & $-27,8$ \\
\hline
\end{tabular}

Источник: Федеральная служба Государственной статистики. Центральная база статистических данных - gks.ru 
Безусловными плюсами предлагаемого второго контура финансирования отраслей реальной экономики, и для электроники, в частности, являются:

- технологическая невозможность выведения неденежных инвестиционных сертификатов из проектного воспроизводственного контура Стратегии, предприятия-исполнители которой получили такое финансирование;

- операционный запрет на любые платежи без встречной поставки товаров, выполнения работ или предоставления услуг, что исключает любые коррупционные и откатные схемы;

- автоматическое исключение влияния инфляции благодаря регулированию ставки демереджа в каждом транше неденежных инвестиционных сертификатов.

Эти и другие преимущества нового средства обращения - «неденежного инвестиционного сертификата» обеспечат независимость отечественной экономики от внешних факторов, в том числе:

1. Президент России кроме подчиняющихся непосредственно ему силовых структур государства получит эффективный инструмент оперативного дофинансирования своих программ и Национальных проектов своевременно и в полном объёме. Это обеспечит здоровую конкуренцию коммерческих банков за клиентов - производителей и потребителей, снижению завышенных залоговых требований и приведению размера коммерческого ссудного процента до конкурентоспособной величины 1-2\% годовых.

2. Выпуск неденежных инвестиционных сертификатов будет выведен из-под регулирования банковско-финансового сектора и поставлен на службу Правительства РФ. «Совет по пропорциям и динамике» при Президенте РФ будет осуществлять регулирование инвестиционного и инновационного процессов без оглядки на внешних регуляторов национальной валютно-финансовой системы, которая под прессингом международных регуляторов вынуждена проводить интересы западных крупнейших транснациональных корпораций даже на рынках России.

3. Появление у российских производителей электроники финансовой альтернативы существенно упростит переговоры с банковским сообществом и позволит им пользоваться традиционными кредитами на существенно более благоприятных для производителей условиях.

4. Применение неденежных инвестиционных сертификатов на всех этапах воспроизводственного цикла при производстве электроники исключит из её цены ссудный банковский процент, который сегодня существенно удорожает себестоимость отечественной продукции. Это повысит ценовую конкурентоспособность российской электроники и позволит существенно улучшить воспроизводственные пропорции на отечественном рынке.

5. Распространение действенности неденежных инвестиционных сертификатов на местный рынок потребительских услуг для работников электронной отрасли создаст мощный стимул для отечественных производителей товаров и услуг, и для развития экономики кластеров малых и средних предприятий, ориентированных на товары народного потребления, вокруг предприятий электроники. Этот мультипликационный инвестиционный эффект предельно быстро оживит предпринимательский климат в стране, позволит лавинообразно увеличить количество рабочих мест, существенно продвинуться в борьбе с бедностью.

Таким образом, представляется целесообразным использовать базовые положения модели двухконтурной национальной валютно-финансовой системы, разработанной в научным сообществом анализируемой монографии, в качестве одного из инструментов реализации Стратегии развития электронной промышленности в отношении наиболее перспективного технологического сегмента экономики. Для этого необходимо в кратчайшие сроки разработать, обсудить с научным сообществом, утвердить условия эксперимента и представить такое согласованное учёными и практиками решение на рассмотрение Президенту России. 


\section{ЛИТЕРАТУРА}

1. Schroder Cr. (2009) Industrielle Arbeitskosten im internationalen Vergleich / IW-Trends 3. 21 p. https://www.iwkoeln.de/fileadmin/publikationen/2016/296545/IW-Trends_2016-03-03_ industrielle Arbeitskosten.pdf.

2. Саррацин T. (2013) Германия: самоликвидация. M.: ACT. 39 c.

3. Султанов Ш. (2021) Россия впереди Америки и Китая / Izborsk-klub, 16.03.2021. https://izborskclub.ru/20793.

4. Указ Президента РФ от 7 мая 2012 г. № 596 (2012) О долгосрочной государственной экономической политике» / Официальный сайт Президента России. http://www.kremlin.ru/acts/ bank/35260.

5. Жданов С. (2021) Большой скачок Китая в будущее: 5 причин, по которым Поднебесная обгоняет Запад в науке и технологиях / Knife.media, 24.05.2021. https://knife.media/hb-china-party.

6. Сколько русских живет в Америке в 2021 году? (2021) Mnogofactov. https://mnogofactov.ru/ raznoe/skolko-po-poslednej-perepisi-naseleniyarusskikh-zhivet-v-amerike-v-2017-godu.html.

7. Распоряжение Правительства РФ от 17 января 2020 г. № 20-р (2020) Стратегии развития электронной промышленности Российской Федерации на период до 2030 года / Гарант. https://www.garant.ru/products/ipo/prime/ doc/73340483.

8. Распоряжение Правительства РФ от 17 января 2020 г. № 20-р (2020) Стратегии развития электронной промышленности Российской
Федерации на период до 2030 года / Гарант. https://www.garant.ru/products/ipo/prime/ doc/73340483.

9. Российская оборонка оказалась в долговом болоте. Интервью Ю. Борисова (2018) Ktovkurse, 0312.2018 . http://ktovkurse.com/rossiya/ rossijskaya-oboronka-okazalas-v-dolgovom-bolote.

10. Жданов C. (2021) Большой скачок Китая в будущее: 5 причин, по которым Поднебесная обгоняет Запад в науке и технологиях / Knife.media, 24.05.2021. https://knife.media/hb-china-party.

11. Звонова Е.А., Кузнецов А.В., Пищик В.Я., Сильвестров С.Н. (2020) Особенности и перспективы построения двухконтурной валютно-финансовой системы на национальном и региональном уровне // Мир новой экономики. № 1. С. 26-33.

12. Экономика России: Кто виноват? и Что делать? (2021) Коллективная монография учёных РЭУ им. Г.В. Плеханова. Москва. Издательство «Добротворение». 222 с.

13. Сильвио Г. (1891) Естественный экономический порядок / Royallib. https://royallib.com/ book/gezel_silvio/estestvenniy_ekonomicheskiy_ poryadok.html

14. Цифровой рубль. Доклад Банка России для общественных консультаций (2020) / Официальный сайт Банка России. https://cbr.ru/analytics/d_ok/ dig_ruble.

15. Официальные курсы рубля Госбанка СССР (2021)/ Официальный сайт Банка России. http://www. cbr.ru/currency_base/gosbankcurs/\#highlight=0фициальные\%7Скурсы\%7Сгосбанка\%7Сссср.

\section{Информация об авторе}

Шпак Василий Викторович - кандидат экономических наук, доцент, Институт микроприборов и систем управления им. Л.Н. Преснухина НИУ «МИЭТ» (Российская Федерация, 124498, г. Зеленоград,

Площадь Шокина, дом 1; e-mail: mishinevaiv@minprom.gov.ru).

\section{V.V. SHPAK,}

National Research University of Electronic Technology (MIET) (Moscow, Russian Federation; e-mail: mishinevaiv@minprom.gov.ru)

\section{DEVELOPMENT STRATEGY FOR THE ELECTRONIC INDUSTRY OF THE RUSSIAN FEDERATION AND ITS FINANCIAL SUPPORT}

UDC: $336.1,336.13,351.72$

https://doi.org/10.22394/2410-132X-2021-7-3-195-204

Abstract: The purpose of the article is to substantiate how to solve the problem set by the President of Russia to achieve sovereignty in the development and production of electronics and electronic component base. The Government developed methods for achieving this goal and approved by the Strategy for the Development of the 
Electronic Industry until 2030. The most powerful and dynamically developing competitor of domestic electronics in China, therefore, it is advisable to consider the development of domestic electronics, having isomorphic processes at individual enterprises and in electronics in China as a scale line. Now a bottleneck in the development of domestic electronics has emerged - this is the lack of proactive and duplicate funding for breakthrough technologies. The article presents an asymmetric version of the response to the total and increasing Western sanctions, the main element of which should be non-monetary investment certificates.

Keywords: electronics industry, strategy, non-monetary investment certificates, electronic component base, demurrage For citation: Shpak V.V. Development Strategy for the Electronic Industry of the Russian Federation and Its Financial Support. The Economics of Science. 2021; 7(3):195-204. (In Russ.) https://doi.org/10.22394/2410-132X-2021-7-3-195-204

\section{REFERENCES}

1. Schroder Cr. (2009) Industrielle Arbeitskosten im internationalen Vergleich / IW-Trends 3. 21 p. https://www.iwkoeln.de/fileadmin/publikationen/2016/296545/IW-Trends_2016-03-03_industrielle_Arbeitskosten.pdf.

2. Sarrazin T. (2013) Germany: self-destruction. Moscow: AST. 39 c. (In Russ.)

3. Sultanov Sh. (2021) Russia ahead of America and China/ Izborsk-klub, 16.03.2021. https://izborskclub.ru/20793. (In Russ.)

4. Decree of the President of the Russian Federation dated 7 May 2012 № 596 (2012) On long-term state economic policy / Official site of the President of Russia. http://www.kremlin.ru/acts/bank/35260. (In Russ.)

5. Zhdanov S. (2021) China's Great Leap into the Future: 5 Reasons why the Celestial Empire is ahead of the West in science and technology / Knife. media, 24.05.2021. https://knife.media/hb-chinaparty. (In Russ.)

6. How many Russians live in America in 2021? (2021) Mnogofactov. https://mnogofactov.ru/raznoe/ skolko-po-poslednej-perepisi-naseleniya-russkikhzhivet-v-amerike-v-2017-godu.html. (In Russ.)

7. Order of the Government of the Russian Federation dated 17 January 2020 № 20-r (2020) Strategy for the development of the electronic industry of the Russian Federation for the period up to 2030 / Garant. https://www.garant.ru/products/ipo/prime/ doc/73340483. (In Russ.)

8. Order of the Government of the Russian Federation dated 17 January 2020 № 20-r (2020) Strategy for the development of the electronic industry of the Russian Federation for the period up to 2030 /
Garant. https://www.garant.ru/products/ipo/ prime/doc/73340483. (In Russ.)

9. The Russian defense industry found itself in a debt swamp. Interview with Yuri Borisov (2018) Ktovkurse, 0312.2018 . http://ktovkurse.com/rossiya/rossijskaya-oboronka-okazalas-v-dolgovombolote. (In Russ.)

10. Zhdanov S. (2021) China's Great Leap into the Future: 5 Reasons why the Celestial Empire is ahead of the West in science and technology / Knife. media, 24.05.2021. https://knife.media/hb-chinaparty. (In Russ.)

11. Zvonova E.A., Kuznetsov A.V., Pishchik V. Ya., Silvestrov S.N. (2020) Features and prospects of building a double-circuit monetary and financial system at the national and regional level // World of a new economy. 2020; 1:26-33. (In Russ.)

12. Economy of Russia: Who is to blame? and What to do? (2021) Collective monograph of scientists of the PRUE. G.V. Plekhanov. Moscow. Publishing house «Dobrotvorenie». 222 c. (In Russ.)

13. Silvio G. (1891) Natural economic order / Royallib. https://royallib.com/book/gezel_silvio/estestvenniy_ekonomicheskiy_poryadok.html. (In Russ.)

14. Digital ruble. Bank of Russia report for public consultations (2020) / Official website of the Bank of Russia. https://cbr.ru/analytics/d_ok/dig_ruble. (In Russ.)

15. Official ruble rates of the USSR State Bank (2021) / Official website of the Bank of Russia. http://www. cbr.ru/currency_base/gosbankcurs/\#highlight= официальные\% $\overline{7}$ Скурсы\%7Сгосбанка\%7Сссср. (In Russ.)

\section{Author}

Vasily V. Shpak - Associate Professor, L.N. Presnukhin Institute of Micro-Devices and Control Systems of NIU "MIET" (Russian Federation, 124498, Zelenograd, Shokin Square, Id. 1; e-mail: mishinevaiv@minprom.gov.ru). 